\title{
Mapping standard ophthalmic outcome sets to metrics currently reported in eight eye hospitals
}

\author{
Monica Michelotti ${ }^{1}$, Dirk F. de Korne ${ }^{2,3,4,5^{*}}$, Jennifer S. Weizer ${ }^{6}$, Paul P. Lee ${ }^{6}$, Declan Flanagann ${ }^{7}$, Simon P. Kelly ${ }^{8}$, \\ Anne Odergren ${ }^{9}$, Sukhpal S. Sandhu ${ }^{10}$, Charity Wai ${ }^{2}$, Niek Klazinga ${ }^{11}$, Aravind Haripriya ${ }^{12}$, Joshua D. Stein ${ }^{6}$ \\ and Melanie Hingorani ${ }^{7}$
}

\begin{abstract}
Background: To determine alignment of proposed international standard outcomes sets for ophthalmic conditions to metrics currently reported by eye hospitals.

Methods: Mixed methods comparative benchmark study, including eight eye hospitals in Australia, India, Singapore, Sweden, U.K., and U.S. All are major international tertiary care and training centers in ophthalmology. Main outcome measure is consistency of ophthalmic outcomes measures reported.

Results: International agreed standard outcomes (ICHOM) sets are available for cataract surgery (10 metrics) and macular degeneration (7 metrics). The eight hospitals reported 22 different metrics for cataract surgery and 2 for macular degeneration, which showed only limited overlap with the proposed ICHOM metrics. None of the hospitals reported patient reported visual functioning or vision-related quality of life outcomes measures (PROMs). Three hospitals (38\%) reported rates for uncomplicated cataract surgeries only. There was marked variation in how and at what point postoperatively visual outcomes following cataract, cornea, glaucoma, strabismus and oculoplastics procedures were reported. Seven (87.5\%) measured post-operative infections and four (50\%) measured 30 day unplanned reoperation rates.
\end{abstract}

Conclusions: Outcomes reporting for ophthalmic conditions currently widely varies across hospitals internationally and does not include patient-reported outcomes. Reaching consensus on measures and consistency in data collection will allow meaningful comparisons and provide an evidence base enabling improved sharing of "best practices" to improve eye care globally. Implementation of international standards is still a major challenge and practice-based knowledge on measures should be one of the inputs of the international standardization process.

Keywords: Outcomes, Measurement, Benchmarking, Quality improvement

\section{Background}

Outcome reporting is mandated in many health care systems, and it is being incorporated into good medical practice and physician maintenance of certification [1, 2]. Several eye care providers and governmental entities indeed publicly report performance,

\footnotetext{
* Correspondence: dirk.de.korne@snec.com.sg; Dirk.de.Korne@kkh.com.sg; dirk.dekorne@duke-nus.edu.sg; dekorne@eshpm.eur.nl

${ }^{2}$ Singapore National Eye Centre, SingHealth Duke-NUS Academic Medical Centre, 11 Third Hospital Avenue, Singapore 168751, Singapore

${ }^{3}$ Medical Innovation \& Care Transformation, KK Women's \& Children's

Hospital, Singapore, Singapore

Full list of author information is available at the end of the article
}

often comparing outcomes with evidence-based benchmarks or targets [3-8]. The objective of reporting outcomes of high volume, high risk, or high cost procedures has been described as optimizing clinical efficacy and patient safety as well as cost-effectiveness [9-11].

Two leading subspecialties in ophthalmology recently developed a global standard outcomes set with the International Consortium of Outcomes Measurement (ICHOM) framework. The first one was for cataract $[12,13]$. Cataract surgery, a removal of an opaque lens and replacement with an artificial intraocular lens 
implantation, is the most frequently performed elective surgical procedure in many countries, and rates of this surgery are likely to continue increasing as access improves in developing countries [14]. The second standard set was developed for macular degeneration, the leading cause of irreversible vision loss, accounting for over $15 \%$ of blindness in high-income countries, with an expected increase of the burden of disease $[15,16]$. The standards sets propose to track preoperative visual acuity and target refraction, patient-reported visual function, intraoperative complications including capsule problems and dropped nucleus as well as other postoperative complications.

However, cataract surgery, macular degeneration and other subspecialties appear to currently have wide variations not only in outcome definition and risk stratification but also in metrics currently publicly reported. Collection of complete, reliable and robust outcome measurements is challenging $[17,18]$ and public reporting of individual surgeon's outcomes in other surgical specialties, such as cardiac surgery, is not without controversy [19-21]. It is important to carefully select outcome measures and use unambiguous, consistent, transparent methodologies, to ensure that data can be reliably compared across institutions internationally [22].

Despite its effectiveness, rates of ophthalmic treatment vary substantially between countries and the need for systematic measurement of outcomes is paramount. One would expect standardized outcomes measures to deliver "value-based cataract care" as theoretically envisioned by Michael Porter and others [23, 24]. In recent years, the policy concept of value-based medicine, and a change in focus from 'volume' to 'value,' have been increasingly discussed within in various health care systems, resulting in tracking of outcomes and changed reimbursement methodologies. Moreover, increased attention to surgical error, patient safety, and healthcare costs has increased public interest in reporting and comparing clinical performance. While the international standard sets are presented, little is known about the actual use of these indicators in hospital practice and the metrics that are currently used for other subspecialties.

In this paper, we map current ophthalmic outcome measures reported by a volunteer sample of major ophthalmic hospitals, which aspire to be exemplars of ophthalmic indicator use internationally to global standard sets, and provide insights into useful metrics to assess performance in ophthalmology and some of the challenges of implementing such measures across institutions.

\section{Methods}

In this mixed methods descriptive study, we performed a review of the outcomes reported and compared this to existing standards [25]. Nine hospitals that are self- declared leaders in the routine publication and use of ophthalmic outcome indicators and that are members of an international eye hospital association were invited to participate in the study. The hospitals are participating in existing operational benchmarking initiatives that have been reported before $[8,26]$ and hence functioned as a convenient sample for the current review study on outcomes. Eight hospitals agreed on participation, and appointed one main point of contact that provided inside information on the availability and use of indicators in the respective hospitals. The websites of the eight hospitals were reviewed for publicly reported outcomes data or metrics on ophthalmic outcomes. Five institutions were found to have published data available on their website (Cole Eye Institute at Cleveland Clinic, University of Michigan W.K. Kellogg Eye Center, Massachusetts Eye and Ear Infirmary, Moorfields Eye Hospital, and Singapore National Eye Center). We searched the Medline, Cochrane, Emerald, Web of knowledge and Web of Science databases to find existing outcomes benchmark data using the following terms: ophthalmology, cataract, macular degeneration, outcomes, metrics, measures, and benchmarks. Preferred Practice Patterns from the American Academy of Ophthalmology (AAO), Clinical Guidelines from the Royal College of Ophthalmologists (RCOphth), and cited targets or benchmarks that each hospital had used were reviewed. In addition to the outcomes data published on the hospitals' websites, non-published measures (eg, annual reports, departmental quality reports, auditing reports) were recorded through the main point of contact in the respective hospitals. Outcomes were added from Aravind Eye Hospital (Madurai, India), Moorfields Eye Hospital (London, United Kingdom), Singapore National Eye Center, The Royal Victorian Eye and Ear Hospital (Melbourne, Australia) and St. Erik's Eye Hospital (Stockholm, Sweden). For the purposes of this paper, and to facilitate the sharing of non-publicly reported data, the hospital names were anonymized when comparing quality performance measures. University of Michigan's and each of the participating hospitals' Institutional Review Boards approvals were waived for this quality of care study.

\section{Results}

Data from eight institutions were available and were grouped according to outcomes measures recommended in the international standard sets.

\section{Cataract surgery}

Outcomes for cataract surgery are listed in Table 1, following the recommended classification of intraoperative and postoperative measures. Preoperative demographics, baseline visual status, ocular comorbidities and 
Table 1 Comparison of ICHOM outcome measures for cataract surgery and reported measures in study hospitals

\begin{tabular}{|c|c|c|c|c|c|}
\hline & Item & $\begin{array}{l}\text { Proposed ICHOM } \\
\text { Measure }\end{array}$ & $\begin{array}{l}\text { Reported Measure } \\
\text { in Study Hospitals }\end{array}$ & $\begin{array}{l}\text { Number of Hospitals } \\
\text { Reporting }\end{array}$ & Reported Value \\
\hline \multirow[t]{5}{*}{ Intraoperative } & \multirow[t]{5}{*}{ Complications } & Capsule problems & Posterior capsule rupture & $6 / 8$ & $0.64-2.11 \%$ \\
\hline & & $\begin{array}{l}\text { Dropped nucleus or lens } \\
\text { fragment into vitreous }\end{array}$ & Retained lens matter & $1 / 8$ & $0.21 \%$ \\
\hline & & \multirow[t]{3}{*}{ Other } & Intraoperative complications & $1 / 8$ & $1.87 \%$ \\
\hline & & & Zonular dialysis & $1 / 8$ & $0.11 \%$ \\
\hline & & & Choroidal hemorrhage & $1 / 8$ & $0.11 \%$ \\
\hline \multirow[t]{12}{*}{ Postoperative } & \multirow[t]{4}{*}{ Visual acuity } & \multirow[t]{4}{*}{ Post-operative visual acuity } & $\begin{array}{l}\text { BCVA } 20 / 40 \text { or better at } 4-6 \text { weeks, } \\
\text { all cases }\end{array}$ & $2 / 8$ & $91 \%$ \\
\hline & & & $\begin{array}{l}\text { BCVA } 20 / 40 \text { or better at } 4-6 \text { weeks, } \\
\text { excluding co pathology }\end{array}$ & $3 / 8$ & $87-100 \%$ \\
\hline & & & $\begin{array}{l}\text { 1-14 letters improvement ETDRS } \\
\text { VA score }\end{array}$ & $1 / 8$ & $\approx 52 \%$ \\
\hline & & & $\begin{array}{l}\geq 15 \text { letters improvement ETDRS } \\
\text { VA score }\end{array}$ & $1 / 8$ & $\approx 42 \%$ \\
\hline & Refractive error & Post-operative refractive error & $\begin{array}{l}\text { Final spherical equivalent within } \\
1 \mathrm{D} \text { of target }\end{array}$ & $5 / 8$ & $85-97 \%$ \\
\hline & $\begin{array}{l}\text { Patient-reported } \\
\text { visual function }\end{array}$ & $\begin{array}{l}\text { Rasch-calibrated score from } \\
\text { Catquest 9SF or other } \\
\text { Rasch-calibrated PROM }\end{array}$ & NA & $0 / 8$ & NA \\
\hline & \multirow[t]{6}{*}{ Complications } & Return to operating theater & $\begin{array}{l}\text { Unplanned reoperation within } \\
30 \text { days of surgery }\end{array}$ & $4 / 8$ & $1.1-1.52 \%$ \\
\hline & & Endophthalmitis rate & Endophthalmitis rate & $6 / 8$ & $0.0-0.07 \%$ \\
\hline & & Persistent corneal edema & NA & $0 / 8$ & NA \\
\hline & & \multirow{3}{*}{$\begin{array}{l}\text { Other (any postoperative } \\
\text { complication within } 3 \text { months } \\
\text { requiring treatment or } \\
\text { compromising outcome) }\end{array}$} & Postoperative complications & $1 / 8$ & $0.36 \%$ \\
\hline & & & Unplanned vitrectomy & $4 / 8$ & $0.48-1.93 \%$ \\
\hline & & & Iris trauma & $1 / 8$ & $0.32 \%$ \\
\hline
\end{tabular}

ETDRS Early Treatment Diabetic Retinopathy Study, BCVA best corrected visual acuity, D Diopter, VA visual acuity

prior ophthalmic interventions are not listed. The eight hospitals reported a total of 22 different metrics for cataract surgery outcomes. None of the hospitals reported patient reported visual functioning. Three hospitals reported rates for uncomplicated cataract surgeries only. Six $(75 \%)$ hospitals reported postoperative visual acuity, of which five (62.5\%) reported postoperative outcomes of best-corrected visual acuity $\geq 20 / 40$. There was marked variation in how and at what point postoperatively visual outcomes following cataract surgery were reported. Five (62.5\%) reported the difference in refraction from the preoperative biometry based target. Seven (87.5\%) measured post-operative infections and four $(50 \%)$ measured 30 day unplanned reoperation rates. Seven institutions (87.5\%) assessed visual acuity, and the most common outcome benchmark reported was bestcorrected visual acuity of $20 / 40$ or better. The most common refractive outcome measured was spherical equivalent within 1 diopter (D) of target refraction. With regard to postoperative complications, none of the hospitals reported on persistent corneal edema while only less then half of the hospitals reported other complications.

\section{Macular degeneration}

Outcomes for macular degeneration are presented in Table 2, following the order of the standard set visual functioning and vision-related quality of life, disutility of care and disease control. Two hospitals (25\%) reported on visual acuity. None of the hospitals reported on mobility and independence, emotional well-being or reading and accessing information. For complications of treatment, the most common measure was endophthalmitis rate following intravitreal injection, presented by five hospitals (62.5\%). None of the hospitals reported the presence of intraretinal or subretinal fluid or hemorrhage.

\section{Other outcomes}

The outcomes of the other ophthalmic procedures reported by the hospitals are presented as Supplementary Data. Refractive surgery outcomes are presented in Additional file 1. Several hospitals report refractive outcomes in detail, which is useful for marketing purposes to potential customers/consumers for such procedures. However, there are many permutations and combinations of refractive treatments and preoperative refractive errors precluding easy comparison. Medical and surgical 
Table 2 Comparison of ICHOM outcome measures for macular degeneration and reported measures in study hospitals

\begin{tabular}{|c|c|c|c|c|c|c|}
\hline & Item & Propose ICHOM Measure & $\begin{array}{l}\text { Reported measure } \\
\text { in study hospitals }\end{array}$ & $\begin{array}{l}\text { Number of } \\
\text { hospitals reporting }\end{array}$ & Target & $\begin{array}{l}\text { Reported } \\
\text { value }\end{array}$ \\
\hline \multirow[t]{5}{*}{$\begin{array}{l}\text { Visual functioning } \\
\text { and vison-related } \\
\text { quality of life }\end{array}$} & \multirow[t]{2}{*}{$\begin{array}{l}\text { Distance } \\
\text { visual acuity }\end{array}$} & \multirow{2}{*}{$\begin{array}{l}\text { Distance visual acuity } \\
\text { (best of uncorrected, } \\
\text { corrected, or pinhole) in } \\
\text { the affected eye. }\end{array}$} & $\begin{array}{l}\text { Gain VA (15 ETDRS letters) } \\
\text { after injections for macular } \\
\text { degeneration }\end{array}$ & $1 / 8$ & $>20 \%$ & $20.7 \%$ \\
\hline & & & $\begin{array}{l}\text { Visual stability } \\
\text { (loss }<15 \text { ETDRS letters) } \\
\text { after injections for } \\
\text { macular degeneration }\end{array}$ & $1 / 8$ & $>80 \%$ & $90.25 \%$ \\
\hline & $\begin{array}{l}\text { Mobility and } \\
\text { independence }\end{array}$ & $\begin{array}{l}\text { Impact of vision impairment } \\
\text { questionnaire }\end{array}$ & NA & $0 / 8$ & None & NA \\
\hline & $\begin{array}{l}\text { Emotional } \\
\text { well-being }\end{array}$ & $\begin{array}{l}\text { Impact of vision impairment } \\
\text { questionnaire }\end{array}$ & NA & $0 / 8$ & None & NA \\
\hline & $\begin{array}{l}\text { Reading and } \\
\text { accessing } \\
\text { information }\end{array}$ & $\begin{array}{l}\text { Impact of vision impairment } \\
\text { questionnaire }\end{array}$ & NA & $0 / 8$ & None & NA \\
\hline \multirow[t]{3}{*}{ Disutility of care } & \multirow[t]{2}{*}{$\begin{array}{l}\text { Number of } \\
\text { treatments }\end{array}$} & \multirow{2}{*}{$\begin{array}{l}\text { Documentation of individual } \\
\text { treatments received for } \\
\text { macular degeneration }\end{array}$} & $\begin{array}{l}\text { Appointment access and } \\
\text { check in (\% best response) }\end{array}$ & $1 / 8$ & None & $\approx 63 \%$ \\
\hline & & & $\begin{array}{l}\text { Clinic wait times and } \\
\text { comfort (\% best response) }\end{array}$ & $1 / 8$ & None & $\approx 45 \%$ \\
\hline & $\begin{array}{l}\text { Complications of } \\
\text { treatment }\end{array}$ & $\begin{array}{l}\text { Endophthalmitis: severe } \\
\text { intraocular inflammation } \\
\text { within } 3 \text { months of last } \\
\text { intraocular treatment }\end{array}$ & $\begin{array}{l}\text { Endophthalmitis after } \\
\text { anti-VEGF intravitreal } \\
\text { injections }\end{array}$ & $5 / 8$ & $\begin{array}{l}\text { None or } \\
0.2-1.9 \%{ }^{\mathrm{a}} \\
0.05 \% \\
\text { (MARINA) }\end{array}$ & $0-0.18 \%$ \\
\hline Disease control & $\begin{array}{l}\text { Presence of } \\
\text { fluid, edema, } \\
\text { or hemorrhage }\end{array}$ & $\begin{array}{l}\text { Presence of intraretinal or } \\
\text { subretinal fluid or hemorrhage } \\
\text { that is attributable to activity } \\
\text { of the neovascular lesion }\end{array}$ & NA & $0 / 8$ & None & NA \\
\hline
\end{tabular}

ETDRS Early Treatment Diabetic Retinopathy Study, $R D$ retinal detachment, VEGF vascular endothelial growth factor, $P V R$ proliferative vitreo-retinopathy

${ }^{a}$ Bhavsar et al. Risk of endophthalmitis after intravitreal drug injection when topical antibiotics are not required. Arch Ophthalmol 2009; 127(12): 1581-1583

retina outcome measures other than related to macular degeneration are shown in Additional file 2. Some institutions risk-stratify surgical retina outcomes by initial surgery or reoperations, while others subdivide cases by specific etiology. Metrics include both functional (visual acuity) and structural (retinal re-attachment rate) outcomes. There is variation in reported outcome measures for pediatric and strabismus surgery, Additional file 3 . Some hospitals measure complications or reoperation rates. There are also two hospitals that measure the postoperative improvement in ocular alignment, with success being defined as less than 10-15 prism diopter of residual eso- or exotropia. Additional file 4 demonstrates glaucoma and corneal surgery outcome measures. The cornea outcomes primarily focus on corneal transplant failure or rejection rate. The expected failure rate differs significantly based on which type of corneal graft, and some institutions differentiate their results based on corneal procedure type. Some hospitals report postoperative visual acuity or improvement following corneal transplant surgery. All institutions measure either intraoperative or postoperative complications with some reporting glaucoma surgery 'failure' or 'success' rates and/or post-operative endophthalmitis rates. The latter is presumed to be early surgery-related endophthalmitis, with little information regarding late blebitis related cases. Two institutions set a goal for intraocular pressure (IOP) of $<17 \mathrm{mmHg}$ or $<21 \mathrm{mmHg}$ and one institution looked at only the change in IOP following surgery. Interestingly, data is not published on the use of antimetabolites (including the re-needling rates with/without antimetabolites) and whether surgery is combined with cataract. Oculoplastics outcome measures are shown in Additional file 5. Some departments measure reoperation rates or complication rates. Two hospitals measure postoperative ptosis repair success - one based on postoperative eyelid symmetry and the other looks at patient satisfaction rates on a scale of 1-10.

\section{Discussion}

We present the first review of ophthalmic outcome measures reported by eye hospitals in diverse populations in various nations. The study is limited by the number of institutions who publicly report outcomes and indicators, and a reluctance from a number of institutions to either devote resource to gather regular indicator results to benchmark or, if gathered, to share or publish indicator results. This rendered a comprehensive or global data gathering study impractical at this time, but the use of a sample of leading institutions was possible and, 
although by necessity only permitting descriptive statistics, does demonstrate both the utility and the issues in attempting to use ophthalmic indicators to benchmark and compare performance across institutions and countries. Although several hospitals report similar outcomes and targets or benchmarks in each subspecialty, there is little congruence on which outcomes or benchmarks should be reported, which methodologies should be used and how to address preoperative risk and co-morbidity. Despite the existence of two internationally agreed ICHOM standards for eye care, compliance with the proposed measures is limited and especially measurement of recommended patient reported visual functioning or vision-related quality of life outcomes measures (PROM's) is not yet taking place systematically. While we realize that health care systems are complex and (large) differences between health systems could be barrier for valid comparisons, [8] other surgical specialties have long recorded outcomes and such reporting has improved clinical and cost effectiveness as well as patient safety [19, 27]. Initial fears of surgeon avoidance of high-risk cases or unfair reputational damage have proved largely unfounded [19]. In the U.K. many surgical specialties publish their outcomes, and in 2016 the first pilot with a national reporting on cataract surgery outcomes was done in a similar fashion [28]. Pay for performance tools have been instituted by Medicare in the US. The Physician Quality Reporting System (PQRS) was initially started as an incentive system to promote quality of care and outcome reporting. In 2017, ophthalmic practices who do not report three quality measures $50 \%$ of time will receive a $2 \%$ penalty on Medicare reimbursements 2 years down the road. Physicians who report nine measures in three of the new national quality strategy domains will receive a $0.5 \%$ bonus payment [29]. With the increasing prevalence of electronic record systems, quality-focused healthcare, rising patient expectations as well as increasing cost pressures, our expectation is that outcome reporting in ophthalmology will globally become the norm instead of the exception.

Goals in clinical outcome reporting include encouraging quality improvement, creating a minimum standard for providers, driving innovation in care, performance management of units and individual surgeons, distributing pay incentives, increasing informed decision making for patients as well as promoting public confidence in healthcare providers, and contributing to research [30, 31]. Reporting outcomes data to the public may promote greater scrutiny of health care and reduce variations in the quality of care, thereby making physicians more accountable [32].

One potentially straightforward method of outcome reporting is to indicate ophthalmic quality and safety by measurement of the rate of serious adverse healthcare associated events such as postoperative infections, unplanned reoperations, and so called 'never events'. 'Never events' are serious, potentially preventable errors in healthcare, for example in cataract care these may include operating on the wrong patient, on the wrong eye, or inserting the incorrect (unplanned) intraocular lens [33]. 'Never events' are taken seriously and investigated with root cause analysis, and actions should be taken to prevent error recurring with a culture of fair blame. There was significant consensus in this area, with all institutions reporting similar values; however some institutions reported only subspecialty-specific data.

In cataract surgery, many institutions report visual acuity - the most common target was best-corrected visual acuity of 20/40 or better, however another strategy is to consider improvement in visual acuity. We found that timing of follow-up for outcome reporting following cataract surgery may be influenced by particular health system or hospital's practice patterns. For example if post-operative cataract patients are discharged from ophthalmic care or followed up in the community the return of outcome data may be problematic.

It is notable that there is a lack of hospitals using patient-reported measures, while patient satisfaction and experience rates are commonly used measure by payers and state agencies. In contrast, while a variety of instruments have been employed in research studies for assessing the impacts of cataract (and other ocular) surgery on patients' symptoms, functional ability, wellbeing and health, these are not yet generally publicly reported in clinical care. These PROM's can be divided into generic assessments that have been designed to apply across a range of different health conditions (for example, the EuroQol EQ-5D and SF-36) and instruments that focus specifically on vision-related conditions (for example, the VF-14). Properly developed PROM's are valid and reliable research tools but they can be cumbersome for patients to use routinely on a large-scale basis [34]. The RCOphth resisted the use of the VF-14 PROM metrics for routine use in the U.K. National Health Services (NHS) cataract surgery for referral or reimbursement purposes, as the College was of the opinion that it added no value in routine NHS care in the U.K. [1]. Subsequent research confirmed the College's concerns about the VF-14 tool [35, 36]. PROM's tools are increasingly being tied to reimbursement and their use is likely to be an area of growth in ophthalmic care the future.

\section{Limitations of current ophthalmic indicator use}

As electronic records become standardized and more patient specific data is readily available, ophthalmic outcome measures will become easier to obtain and potentially more meaningful. The merit of quality reporting depends on data quality, risk adjustment, sample size, and the specification of quality measures themselves [37]. Current ophthalmic 
outcomes reporting methods do not usually take into account the complicated statistical methods for risk adjustment used in other healthcare fields and hence we have not applied any quantitative comparison or statistical tests in this study. The issue of case mix adjustments is a critical topic in other specialties that publicly report outcomes. Failure to adjust for such may discourage surgeons from treating high-risk patients and therefore deny high-risk patients the opportunity of benefiting from surgery, while appropriate risk adjustment can do much to allay these concerns. There has been reported reluctance of some cardiac surgeons to operate on high-risk patients for these reasons [38, 39] and, without appropriate risk adjustment, unintended distortions of appropriate surgical care may thus arise to the ultimate detriment of the public [40].

At present, hierarchical regression is the gold standard for risk adjustment of outcomes and for producing provider report cards; however this gold standard is rarely used [41] and no equivalent modeling has been developed in ophthalmology to date. The National Ophthalmic Database (NOD) in the U.K. has compiled a national cataract data set, and participating cataract surgeons have the ability to compare their individual surgical data to others in a risk-adjusted manner [28]. A new American registry [42] may have the ability to risk stratify eye surgeons' case mix, while previous groups have either excluded any patients with comorbidities or not performed case mix analysis.

\section{Next steps}

Increasingly, there are national and multi-national collaborations that are collecting large quantities of data on structures, processes, and outcomes of care, and this is facilitated by increasing use of electronic health records which removes many previous barriers to large scale data gathering. These databases will become more prominent and powerful with their ability to retrieve data directly from electronic medical records.

The European Registry of Quality Outcomes for Cataract and Refractive Surgery (EUREQUO) was initiated in 2008 by 11 European countries to improve treatment and standards of care for cataract and refractive surgery and to develop evidence based guidelines [43]. As of mid-2016, more than 2 million cataract operations were included in the database and specific guidelines were established regarding cataract surgery. These guidelines, in addition to the benchmark set by Hahn and colleagues [44] for cataract surgery, may be useful benchmarks for other organizations to use.

The Intelligent Research in Sight (IRIS) registry is a clinical data registry designed by the American Academy of Ophthalmology (AAO) that opened to all AAO member physicians since 2014. This registry automatically collects data from participating electronic health record systems and provide benchmark reports for participating practitioners. As of 1 January 2016, the IRIS registry included 11,739 physicians, and registered 72.05 million visits representing 20.5 million patients presumably $[45,46]$.

Finally, ICHOM's standard guideline sets for cataract surgery [13] and macular degeneration [15] have been rigorously developed with the goal of improving quality of health care, reducing health care costs, and supporting informed decision-making. As the currently reported outcomes were found to be only partially in line with the standards, in some instances the ICHOM sets might need to shift to align with what is currently done. In most instances, however, institutions might opt to align their reporting with the standard sets, which is the direction the institutions participating in our study are currently taking.

Our study shows that much more alignment on the concept of value based eye care will be needed to implement the standards in the day-to-day hospital practice and gives suggestions for future metrics in other subspecialties to be developed. Practice-based knowledge on outcome measures, as provided in this paper, should form part of the input of the international standardization process to assure implementation.

\section{Conclusion}

Outcomes reporting for ophthalmic surgery currently widely varies across hospitals globally, and value too often seems to be defined in the eyes of the beholder. Reaching consensus on outcomes measures will allow meaningful comparisons of outcomes at different hospitals which will provide an evidence base enabling improved sharing of "best practices" to improve eye care globally. Identifying standardized and common metrics is an important first step to improve the quality of outcome data. As data improves and methods of risk adjustment become more mature, outcome metrics can help institutions to improve the quality of the patient care they provide and demonstrate this quality to patients, payers of healthcare and regulators. However, setting of international standards on outcomes should include practice-based knowledge, as provided through the mapping exercise in this paper, from the beginning.

\section{Additional files}

Additional file 1: Refractive and corneal outcomes reported by the hospitals. Description of date: 32 refractive and corneal outcomes reported by the hospitals. (DOCX $18 \mathrm{~kb}$ )

Additional file 2: Retinal outcomes reported by the hospitals. Description of data: 35 retinal outcomes reported by the hospitals. (DOCX 19 kb)

Additional file 3: Pediatrics and strabismus outcomes reported by the hospitals. Description of data: 15 Pediatrics and strabismus outcomes reported by the hospitals. (DOCX $17 \mathrm{~kb}$ ) 
Additional file 4: Cornea and glaucoma outcomes reported by the hospitals. Description of data: 29 cornea and glaucoma outcomes reported by the hospitals. (DOCX $20 \mathrm{~kb}$ )

Additional file 5: Oculoplastics outcomes reported by the hospitals. Description of the data: 11 oculoplastics outcomes reported by the hospitals. (DOCX $16 \mathrm{~kb}$ )

\section{Abbreviations}

AAO: American Academy of Ophthalmology; EQ-5D: EuroQual 5D; EUREQUO: European Registry of Quality Outcomes for Cataract and Refractive Surgery; ICHOM: International consortium for health outcomes measurement; IOP: Intraocular pressure; IRIS: Intelligent Research in Sight; NHS: National Health Services; NOD: National Ophthalmic Database; PQRS: Physician Quality Reporting System; PROM: Patient reported outcomes measure; SF-36: 36-item short form survey; VF-14: Visual functioning index 14, WAEH: World Association of Eye Hospitals

\section{Acknowledgements}

We are grateful to the World Association of Eye Hospitals (WAEH) (www.waeh.org) for providing access to their member institutes, and to Aravind Eye Hospital, Madurai, India, for providing a presentation platform to present preliminary data.

\section{Funding}

This work was supported by the Michigan Ophthalmology Trainee Career Development Award, University of Michigan, Ann Arbor. The sponsor had no role in the design or conduct of this research.

\section{Availability of data and materials}

All data generated or analysed during this study are included in this published article and its 5 supplementary information files.

\section{Authors' contributions}

MM carried out the data gathering and analysis and co-drafted the manuscript. DK performed the comparisons with the standard sets, and co-drafted, and revised the manuscript. $\mathrm{MH}$, JS, and JW conceived of the study and participated in the design. PL, DF, SK, AO and SS were involved analysis and interpretations of the clinical outcomes. $\mathrm{CW}, \mathrm{NK}$ and $\mathrm{AH}$ were involved in the design of the study, the interpretation of the comparisons with the standard sets and revising the manuscript. All authors read and approved the final manuscript, take public responsibility for the content and are accountable for all aspects of the work

\section{Ethics approval and consent to participate}

University of Michigan's and each of the participating hospitals' Institutional Review Boards approvals were waived for this quality of care study.

\section{Consent for publication}

Not applicable

\section{Competing interests}

The authors declare that they have no competing interests.

\section{Publisher's Note}

Springer Nature remains neutral with regard to jurisdictional claims in published maps and institutional affiliations.

\footnotetext{
Author details

${ }^{1}$ Casey Eye Institute, Oregon Health and Sciences University, Portland, OR, USA. ${ }^{2}$ Singapore National Eye Centre, SingHealth Duke-NUS Academic Medical Centre, 11 Third Hospital Avenue, Singapore 168751, Singapore. ${ }^{3}$ Medical Innovation \& Care Transformation, KK Women's \& Children's Hospital, Singapore, Singapore. ${ }^{4}$ Health Services \& Systems Research, Duke-NUS Medical School, Singapore, Singapore. ${ }^{5}$ Erasmus School of Health Policy \& Management, Erasmus University Rotterdam, Rotterdam, Netherlands. ${ }^{6}$ Department of Ophthalmology and Visual Sciences, W.K. Kellogg Eye Center, University of Michigan, Ann Arbor, USA. ${ }^{7}$ Moorfields Eye Hospital NHS Foundation Trust, London, UK. ${ }^{8}$ Department of Ophthalmology, Royal Bolton Hospital, Bolton, UK. ${ }^{9}$ St Eriks Eye Hospital, Stockholm, Sweden.

${ }^{10}$ The Royal Victorian Eye and Ear Hospital, Centre for Eye Research Australia,
}

University of Melbourne, Melbourne, Victoria, Australia. ${ }^{11}$ Department of Social Medicine, Academic Medical Centre, University of Amsterdam, Amsterdam, Netherlands. ${ }^{12}$ Cataract Services, Aravind Eye Care System, Chennai, India.

Received: 12 July 2017 Accepted: 20 December 2017

Published online: 29 December 2017

\section{References}

1. Royal College of Ophthalmologists, Cataract Surgery Guidelines. Available at: https://my.clevelandclinic.org/-/scassets/files/org/outcomes/outcomes-eye. ashx?la=en. Accessed 26 Dec 2017

2. General Medical Council, Good Medical Practice framework for appraisal and revalidation. Available at: http://www.gmc-uk.org/static/documents/ content/GMC_Revalidation_A4_Guidance_GMP_Framework_04.pdf. Last accessed 24 Nov 2016

3. Cole Eye Institute, Cleveland Clinic, 2016 Outcomes. Available at: https://my clevelandclinic.org/-/scassets/files/org/outcomes/outcomes-eye.ashx?la=en. Last accessed 26 Dec 2017.

4. Moorfields Eye Hospital NHS Foundation Trust, Clinical quality \& safety performance report 2015. Available at: http://www.moorfields.nhs.uk/sites/ default/files/Quality\%20and\%20safety\%20\%20report\%20Q23\%202014-15.pdf. Last accessed 24 Nov 2016

5. Massachusetts Eye and Ear, 2015 Quality \& outcomes book. Available at: https://www.masseyeandear.org/about-us/quality-measures/quality-andoutcomes-book. Last accessed 24 Nov 2016.

6. Finn AP, Borboli-Gerogiannis S, Brauner S, Peggy Chang HY, Chen S, Gardiner M, Greenstein SH, Kloek C, Miller JW, Chen TC. Assessing resident cataract surgery outcomes using Medicare Physician Quality Reporting System Measures. J Surg Edu. 2016;73(5):774-9.

7. Singapore National Eye Centre, Clinical Outcome Results. Available at: https://www.snec.com.sg/clinicalservices/clinical-outcome-results/Pages/ home.aspx. Last accessed 24 Nov 2016.

8. de Korne DF, Sol JC, van Wijngaarden JD, van Vliet EJ, Custers T, Cubbon M, Spileers W, Ygge J, Ang C-L, Klazinga NS. Evaluation of an international benchmarking initiative in nine eye hospitals. Health Care Manag Rev. 2010; 35(1):23-35.

9. Schachat AP, Lee PP, Wu WC. A quality assurance program for an inpatient department of ophthalmology. Indicators and criteria. Arch Ophthalmol. 1989;107:1293-6.

10. Mant J. Process versus outcomes indicators in the assessment of quality in health care. Int J Qual Health Care. 2001:13(6):475-80.

11. Parra E, Arenas MD, Alonso M, Martinez MF, Gamen A, Aguaron J, Escobar MT, Moreno-Jiminez JM, Alvarez-Ude F. Assessing value-based health care delivery for haemodialysis. J Eval Clin Pract. 2015; https://doi.org/10.1111/ jep.12483.

12. World Health Organization. Fact sheet no 282 visual impairment and blindness. 2014. http://www.who.int/mediacentre/factsheets/fs282/en/. Last accessed 24 Nov 2016.

13. Mahmud I, Kelly T, Stowell C, Haripriya A, Boman A, Kossler I, Morlet N, Pershing S, Pesudovs K, Goh PP, Sparrow JM, Lundstrom M. A proposed minimum standard set of outcomes measures for cataract surgery. JAMA Ophthalmol. 2015:133(11):1247-52.

14. Schein OD, Banta JT, Chen T, et al. Lesson learned: wrong intra ocular lens. Ophthalmology. 2012:119(10):2059-64.

15. Rodrigues IA, Sprinkhuizen SM, Barthelmes D, Blumenkranz M, Cheung G, Haller J, Johnston R, Kim R, Klaver C, McKibbin M, Ngaf NF, Pershing S, Shandar D, Tamura H, Tufail A, Weng CY, Westborg I, Yelf C, Yoshimura N, Gillies MC. Defining a minimum set of standardized patient-centred outcomes measures for macular degeneration. Am J Ophthalmol. 2016;168:1-12.

16. Minassian DC, Reidy A, Lightstone A, Desai P. Modelling the prevalence of age-related macular degeneration (2010-2020) in the UK: expected impact of antivascular endothelial growth factor (VEGF) therapy. Br J Ophthalmol. 2011:95(10):1433-6.

17. Kelly SP, Mathews D, Mathews J, Vail A. Reflective consideration of postoperative endophthalmitis as a quality marker. Eye (Lond). 2007;21(11): 1419-26.

18. Coleman AL, Morgenstern H. Use of insurance claims databases to evaluate the outcomes of ophthalmic surgery. Surv Ophthalmol. 1997;42(3):271-8.

19. Bridgewater B, Grayson AD, Brooks N, Grotte G, Fabri BM, Au J, Hooper T, Jones M, Keogh B. Has the publication of cardiac surgery outcome data 
been associated with changes in practice in northwest England: an analysis of 25,730 patients undergoing CABG surgery under 30 surgeons over eight years. Heart. 2007;93(6):744-8.

20. Chassin MR, Hannan EL, DeBuono BA. Benefits and hazards of reporting medical outcomes publicly. N Engl J Med. 1996;334:394-8.

21. Werner RM, Asch DA. The unintended consequences of publicly reporting quality information. JAMA. 2005;293:1239-44.

22. Forde I, Morgan D, Klazinga NS. Resolving the challenges in the international comparison of health systems: the must do's and trade-offs. Health Policy. 2013;112(1-2):4-8.

23. Porter ME. What is value in health care? N Engl J Med. 2010;363(26):2477-81.

24. Van Vliet EJ, Bredenhoff E, Sermeus W, Kop LM, Sol JC, van Harten WH Exploring the relation between process design and efficiency in highvolume cataract pathways from a lean thinking perspective. Int J Qual Health Care. 2011;23(1):83-93.

25. Ovretveit J. Evaluating improvement and implementation for health. New York: Open University Press; 2014.

26. de Korne DF, van Wijngaarden JD, Sol JC, Betz R, Thomas RC, Schein OD, Klazinga NS. Hospital benchmarking: are U.S. eye hospitals ready? Health Care Manag Rev. 2012;37(2):187-98

27. Grover FL, Shroyer AL, Hammermeister K, Edwards FH, Ferguson TB Jr, Dziuban SW Jr, Cleveland JC Jr, Clark RE, MCDonald G. A decade's experience with quality improvement in cardiac surgery using the veterans affairs and society of thoracic surgeons national databases. Ann Surg. 2001;234(4):464-72.

28. National Ophthalmology Database Audit 2016. Healthcare quality improvement partnership procurement of national ophthalmology audit. Available at: http://www.hqip.org.uk/public/cms/253/625/19/539/ National\%200pthalmolog y\%20Database\%20Audit\%20Annual\%20Report\%202016.pdf?realName= pokDPB.pdf\&v=0. Last accessed 25 Nov 2016.

29. Physician Quality Reporting System (PQRS) 2016 Ophthalmic specific measures. Available at: https://www.aao.org/practice-management/ regulatory/pqrs-measure-specifications. Last accessed 26 Nov 2016.

30. Mason A, Street A. Publishing outcome data: is it an effective approach? J Eval Clin Pract. 2006;12(1):37-48

31. Dziuban SW, Mcllduff JB, Miller SJ, Dal Col RH. How a New York cardiac surgery program uses outcomes data. Ann Thorac Surg. 1994;58(6):1871-6.

32. Davies H. Falling public trust in health services: implications for accountability. J Health Serv Res Policy. 1999;4(4):193-4.

33. Kelly SP, Jalil A. Wrong intraocular lens implant; learning from reported patient safety incidents. Eye. 2011;25(6):730-4.

34. US Department of Health \& Human Services FDA. Patient reported outcome measures: use in medical product development to support labelling claims. Maryland: Department of Health \& Human Support Food \& Drug Administration; 2009.

35. Black N, Browne J, van der Meulen J, Jamieson L, Copley L, Lewsey J. Is there overutilisation of cataract surgery in England? Br J Ophthalmol. 2009;93(1):13-7.

36. Fung SS, Luis J, Hussain B, Bunce C, Hingorani M, Hancox J. Patient reported outcome measuring tools in cataract surgery-clinical comparison in a tertiary hospital. J Cataract Refract Surg. 2016;42(12):1759-67.

37. Mukamel DB, Glance LG, Dick AW, Osler TM. Measuring quality for public reporting of health provider quality: making it meaningful to patients. Am J Public Health. 2010;100(2):264-9.

38. Schneider EC, Epstein AM. Influence of cardiac-surgery performance reports on referral practices and access to care. A survey of cardiovascular specialists. N Engl J Med. 1996;335(4):251-6.

39. Keogh BE, Kinsman R. National adult cardiac surgical database report 2000-2001. London: Society of Cardio- thoracic Surgeons of Great Britain and Ireland; 2002.

40. Sparrow JM. Cataract surgery: benchmarks for established and trainee surgeons. Eye (Lond). 2008:22(11):1371-2.

41. Ferraris VA, Ferraris SP, Wehner PS, Setser ER. The dangers of gathering data: surgeon-specific outcomes revisited. Int J Angiol. 2011:20(4):223-8.

42. Intelligent Research In Sight (IRIS) Registry. Available at: https://www.aao. org/iris-registry/about. Last accessed 25 June 2017.

43. Lundström M, Barry P, Henry $Y$, Rosen P, Stenevi U. Evidence-based guidelines for cataract surgery: guidelines based on data in the European registry of quality outcomes for cataract and refractive surgery database. J Cataract Refract Surg. 2012;38(6):1086-93.
44. Hahn U, Krummenauer F, Kölbl B, Neuhann T, Schayan-Araghi K, Schmickler S, von Wolff K, Weindler J, Will T, Neuhann I. Determination of valid benchmarks for outcome indicators in cataract surgery: a multicenter, prospective cohort trial. Ophthalmology. 2011;118(11):2105-12.

45. Parke DW, Lum F, Rich WL. The IRIS registry: purposes and perspectives. Ophtalmolog. 2016;113(6):463-8.

46. Coleman AL. How big data informs us about cataract surgery Am J Ophthalmol. 2015;160(6):1091-103.

\section{Submit your next manuscript to BioMed Central and we will help you at every step:}

- We accept pre-submission inquiries

- Our selector tool helps you to find the most relevant journal

- We provide round the clock customer support

- Convenient online submission

- Thorough peer review

- Inclusion in PubMed and all major indexing services

- Maximum visibility for your research

Submit your manuscript at www.biomedcentral.com/submit 